\title{
INTEGRATED USE OF BEDSIDE LUNG ULTRASOUND AND ECHOCARDIOGRAPHY AS AIDING PREDICTORS IN SUCCESSFUL WEANING PROCESS
}

\author{
By \\ Ahmed Mohamed Abdalla Beshir, Ismael Abd El-Menem Attia, \\ Mahmoud El-Saeed Ahmed, Ebrahim Faragallah Saeed* \\ Departments of Chest disease and Cardiology*, Faculty of Medicine, Al-Azhar University \\ Corresponding authors: Ahmed Mohamed Abdalla Beshir, \\ Mobile: +201288845932, E-mail: ahmedbeshir.6@azhar.edu.eg
}

\begin{abstract}
Background: We hypothesized that bedside lung ultrasound (LUS) and echocardiography could be a predictor of postextubation distress by detecting a high lung aeration defect immediately before weaning by evidencing significant lung derecruitment during the spontaneous breathing trial (SBT).

Objective: To evaluate the effectiveness of Lung Ultrasound (LUS) and Transthoracic Echocardiography (TTE) in predicting successful weaning of mechanically ventilated patients.

Patients and Methods: This study was performed on 50 mechanically ventilated patients in general and respiratory ICU during the period from August 2019 to January 2021, at Bab-Al-Sha'reia University Hospital. Lung ultrasound and echocardiography were determined before and at the end of a 60-min spontaneous breathing trial (SBT) and $4 \mathrm{hrs}$. after extubation. To quantify lung aeration, a lung ultrasound score was calculated.

Results: Forty-five patients had SBT success (90\%) and 5 patients experienced SBT failure (10\%), From those patients with SBT success, there were 16 patients $(35.56 \%)$ had post extubation distress, and 29 patients $(64.44 \%)$ had post extubation success. In patients who successfully passed the SBT, a lung ultrasound score $\leq 10$ at the end of the SBT was highly predictive of postextubation success with a statistically significant difference ( $p$ value $<0.001$ ). On the other hand, lung ultrasound score $\geq 18$ at the end of the SBT was highly predictive of postextubation distress with a statistically significant difference ( $\mathrm{p}$ value $<0.001$ ). We found significant differences in E/A ratio $1.08 \pm 0.2$ in patients with spontaneous breathing trial success, and $1.6 \pm 0.1$ in patients with SBT failure with a statistical significant (p-value $<0.001$ ).
\end{abstract}

Conclusion: LUS and TTE during spontaneous breathing trial may accurately predict postextubation distress.

Key Words: Lung ultrasound, diastolic dysfunction, mechanical ventilation, postextubation distress, reintubation, weaning.

\section{INTRODUCTION}

Unnecessary extubation delays can increase the morbidity and mortality associated with prolonged ventilation. Nevertheless, trying to decide when to extubate patients from mechanical ventilation can be challenging for the clinician and has been reported by some to be more art than science (Peouelas et al., 2011). 
Most proposed predictors of postextubation distress either require special equip-ment are too complex for bedside use, or have a limited predictive value (Nemer et al., 2011).

There are no simple clinical indices known to be powerful predictors of postextubation distress. Many mechanisms whose relative weights vary from one patient to another may have an impact on the ability to wean from me $\neg$ chanical ventilation (Heunks and van der Hoeven, 2010).

Lung ultrasound (LUS) could be a predictor of postextubation distress by detecting a high lung aeration defect im $\neg$ mediately before weaning and/or by evidencing significant lung derecruitment during the SBT (Boles et al., 2011).

Cardiac dysfunction is another leading cause of weaning failure. The abrupt cessation of positive pressure ventilation increases venous return and left ventricular (LV) afterload, decreases LV compliance, and may even induce cardiac ischemia. All these factors tend to increase LV filling pressure, and may subsequently result in cardiogenic pulmonary edema (Girard et al., 2017).
The aim of this work was to evaluate the effectiveness of LUS and TTE in predicting successful weaning of mechanically ventilated patients.

\section{PATIENTS AND METHODS}

Study design: This was a prospective study for evaluation the use of (LUS) and (TTE) in predicting successful weaning of mechanically ventilated patients. It was performed on 50 mechanically ventilated patients in general and respiratory ICU during the period from August 2019 to January 2021, at Bab-Al-Sha'reia University Hospital.

\section{Data collection:}

1. Data were collected from these patients: Demographic data, clinical diagnosis, days of admission, cause of mechanical ventilation, days of mechanical ventilation, underlying cardiac and pulmonary diseases, and Simplified Acute Physiology Score (SAPS II).

2. LUS scoring to detect lung aeration defect before and at the end of a 60min spontaneous breathing trial and 4 hrs. after extubation (Table 1).

Table (1): Lung US score for detection of the degree of lung aeration

\begin{tabular}{|c|c|c|}
\hline $\begin{array}{c}\text { Points for each lung } \\
\text { zone (12 zones) }\end{array}$ & Degree of lung aeration & Pattern \\
\hline 0 point & Normal aeration & $\begin{array}{c}\text { Horizontal A-line (no more } \\
\text { than two B-line) }\end{array}$ \\
\hline 1 point & Moderate loss of aeration & $\begin{array}{c}\text { Multiple B-line either regularly } \\
\text { spaced or irregularly spaced }\end{array}$ \\
\hline 2 points & Severe loss of aeration & Multiple coalescent B-lines \\
\hline 3 points & Complete loss of aeration & Lung consolidation \\
\hline Total score & \multicolumn{2}{|c|}{ From 0 to 3} \\
\hline
\end{tabular}


3. TTE at the end of a 60-min spontaneous breathing trial for assessment of fractional area changes, peak velocity of early and late mitral flow, ratio between early and late mitral flow, and deceleration time of velocity of early mitral flow.

Inclusion criteria: Patients mechanically ventilated for more than $48 \mathrm{hrs}$. when the underlying respiratory disease that has required intubation was considered by the attending physician as reversed, rendering the patient eligible to1-hr SBT.

Exclusion criteria: Patients aged <18 yrs., patients with tracheostomy,
Paraplegia with medullar level above T8, significant cardiac arrhythmias and severe ICU-acquired neuromyopathy.

Statistical analysis: Data were analyzed using Statistical package for the Social Sciences (SPSS) version 15.0. Quantitative data were expressed as mean \pm standard deviation (SD) and were compared by independent t-test. Qualitative data were expressed as frequency and percentage and were compared by Chi square test.

\section{RESULTS}

As regard spontaneous breathing trial, there were success in 45 patients (90\%) and failure in 5 patients $(10 \%)$. As regard post extubation distress/success, there were distress in 16 patients $(35.5 \%)$ and success in 29 patients (64.4\%) (Table 2).

Table (2): Description of spontaneous breathing trial and post extubation distress/success in all studied patients

\begin{tabular}{|c|l|c|c|}
\hline \multicolumn{2}{|c|}{} & \multicolumn{2}{c|}{$\begin{array}{c}\text { Studied patients } \\
(\mathbf{N}=\mathbf{5 0})\end{array}$} \\
\hline \multirow{2}{*}{ Spontaneous breathing trial } & Success & 45 & $90 \%$ \\
\cline { 2 - 4 } & Failure & 5 & $10 \%$ \\
\hline \multirow{2}{*}{ Post extubation } & Distress & 16 & $35.56 \%$ \\
\cline { 2 - 4 } & Success & 29 & $64.44 \%$ \\
\hline
\end{tabular}


No statistical significant difference of diagnosis, MV causes and associated diseases as regard spontaneous breathing trial. Statistically significant difference of simplified acute physiologic score II, duration of MV, ICU stay and ICU mortality were as regard spontaneous breathing trial (Table 3).

Table (3): Comparison of clinical data as regard spontaneous breathing trial

\begin{tabular}{|c|c|c|c|c|c|c|}
\hline \multicolumn{2}{|c|}{$\begin{array}{lr}\text { Spontaneous } \\
\text { Parameters } \\
\text { breathing trial }\end{array}$} & \multicolumn{2}{|c|}{$\begin{array}{l}\text { Success } \\
(n=45)\end{array}$} & \multicolumn{2}{|c|}{$\begin{array}{l}\text { Failure } \\
(\mathbf{n}=5)\end{array}$} & P-value \\
\hline \multirow{2}{*}{ Diagnosis } & Medical & 32 & $71.1 \%$ & 3 & $60 \%$ & \multirow{2}{*}{0.607} \\
\hline & Surgical & 13 & $28.9 \%$ & 2 & $40 \%$ & \\
\hline \multirow{5}{*}{ MV causes } & $\begin{array}{l}\text { Respiratory } \\
\text { failure }\end{array}$ & 14 & $31.1 \%$ & 1 & $20 \%$ & \multirow{5}{*}{0.946} \\
\hline & Multiple trauma & 8 & $17.8 \%$ & 1 & $20 \%$ & \\
\hline & $\begin{array}{l}\text { Non-traumatic } \\
\text { coma }\end{array}$ & 2 & $4.4 \%$ & 0 & $0 \%$ & \\
\hline & $\begin{array}{c}\text { Severe } \\
\text { hemodynamic } \\
\text { instability }\end{array}$ & 16 & $35.6 \%$ & 2 & $40 \%$ & \\
\hline & $\begin{array}{l}\text { Post-operative } \\
\text { complication of } \\
\text { abdominal } \\
\text { surgery }\end{array}$ & 5 & $11.1 \%$ & 1 & $20 \%$ & \\
\hline \multirow{4}{*}{ Associated diseases } & None & 6 & $13.3 \%$ & 0 & $0 \%$ & \multirow{4}{*}{0.665} \\
\hline & $\begin{array}{c}\text { Pulmonary } \\
\text { disease }\end{array}$ & 21 & $46.7 \%$ & 3 & $60 \%$ & \\
\hline & $\begin{array}{c}\text { Cardiovascular } \\
\text { disease }\end{array}$ & 14 & $31.1 \%$ & 1 & $20 \%$ & \\
\hline & $\begin{array}{l}\text { Cardiovascular } \\
\text { disease and } \\
\text { pulmonary disease }\end{array}$ & 4 & $8.9 \%$ & 1 & $20 \%$ & \\
\hline $\begin{array}{c}\text { Simplified Acute } \\
\text { Physiologic Score II }\end{array}$ & Mean \pm SD & \multicolumn{2}{|c|}{$49.9 \pm 12.5$} & \multicolumn{2}{|c|}{$66.8 \pm 14.7$} & $0.013 *$ \\
\hline $\begin{array}{c}\text { Duration of MV } \\
\text { (days) }\end{array}$ & Mean \pm SD & \multicolumn{2}{|c|}{$5.2 \pm 1.4$} & \multicolumn{2}{|c|}{$7.4 \pm 0.9$} & $0.002 *$ \\
\hline ICU stay (days) & Mean \pm SD & \multicolumn{2}{|c|}{$11.6 \pm 5.5$} & \multicolumn{2}{|c|}{$19.8 \pm 3.03$} & 0.004* \\
\hline \multirow{2}{*}{ ICU mortality } & No & 41 & $91.1 \%$ & 3 & $60 \%$ & \multirow{2}{*}{0.042} \\
\hline & Yes & 4 & $8.9 \%$ & 2 & $40 \%$ & \\
\hline
\end{tabular}

*: Mann Whitney U test. 
There was a statistical significant difference of LUS (before SBT, End of
SBT \& H4 post-extubation) as regard post-extubation success/distress (Table 4).

Table (4): Comparison of LUS as regard post-extubation success/distress.

\begin{tabular}{|c|c|c|c|c|}
\hline \multicolumn{2}{|c|}{ Post-extubation } & $\begin{array}{c}\text { Distress } \\
(\mathbf{n = 1 6})\end{array}$ & $\begin{array}{c}\text { Success } \\
(\mathbf{n = 2 9})\end{array}$ & P-value \\
\hline Parameters & Mean \pm SD & $15.3 \pm 1.4$ & $9.8 \pm 2.5$ & $<\mathbf{0 . 0 0 1 *}$ \\
\hline LUS before SBT & Mean \pm SD & $18.3 \pm 1.1$ & $9.8 \pm 2.5$ & $<\mathbf{0 . 0 0 1 *}$ \\
\hline LUS end of SBT & Mean \pm SD & $20.3 \pm 5.4$ & $10.4 \pm 2.8$ & $<\mathbf{0 . 0 0 1 *}$ \\
\hline
\end{tabular}

*: Mann Whitney U test.

No statistical significant difference of fractional area change (\%), peak velocity of late mitral flow, and deceleration time of velocity of early mitral flow as regard spontaneous breathing trial. Statistical significant difference of peak velocity was of early mitral flow and ratio between early and late mitral flow as regard spontaneous breathing trial (Table 5).

Table (5): Comparison of ECHO as regard spontaneous breathing trial

\begin{tabular}{|c|c|c|c|c|}
\hline Parameters & $\begin{array}{l}\text { pontaneous } \\
\text { athing trial } \\
\end{array}$ & $\begin{array}{l}\text { Success } \\
(n=45)\end{array}$ & $\begin{array}{c}\text { Failure } \\
(\mathbf{n}=5)\end{array}$ & P-value \\
\hline Fractional area change $(\%)$ & Mean \pm SD & $45.5 \pm 4.3$ & $48.6 \pm 4.5$ & 0.141 \\
\hline $\begin{array}{l}\begin{array}{l}\text { Peak velocity of early mitral flow } \\
(\mathrm{m} / \mathrm{sec})\end{array} \\
\end{array}$ & Mean \pm SD & $0.79 \pm 0.08$ & $1.06 \pm 0.08$ & $<0.001$ \\
\hline $\begin{array}{l}\text { Peak velocity of late mitral flow } \\
(\mathrm{m} / \mathrm{sec})\end{array}$ & Mean \pm SD & $0.73 \pm 0.11$ & $0.68 \pm 0.08$ & 0.309 \\
\hline $\begin{array}{c}\text { Ratio between early and late } \\
\text { mitral flow }\end{array}$ & Mean \pm SD & $1.08 \pm 0.2$ & $1.6 \pm 0.1$ & $<0.001$ \\
\hline $\begin{array}{c}\text { Deceleration time of velocity of } \\
\text { early mitral flow (msec) }\end{array}$ & Mean \pm SD & $169.7 \pm 21.3$ & $181.2 \pm 39$ & \\
\hline
\end{tabular}

\section{DISCUSSION}

Unnecessary extubation delays can increase the morbidity and mortality associated with prolonged ventilation. Nevertheless, trying to decide when to extubate patients from mechanical ventilation can be challenging for the clinician and has been reported by some to be more art than science (Peouelas et al., 2011).

As regard simplified acute physiologic score II (SAPSII) in our study the mean of SAPSII in patients with spontaneous breathing trial success and in patients with
Spontaneous breathing trial failure showed a statistical significant difference. On the other hand the mean of SAPSII in patients with post extubation distress and in patients with post extubation success it showed a statistical significant difference. In contrary to our result, Soummer et al. (2012) and Sliva et al. (2017) found that SAPS II has no statistical significance in predicting weaning failure.

Despite elevated SAPS II at admission, ICU-mortality rate was low (12\%) in agreement with Soummer et al. (2012) with mortality (8\%) and Sliva et al. (2017) with mortality $(10 \%)$. The fact that the 
SAPS II score on admission was not associated with death may be explained by the significant proportion of patients that died before any weaning attempt was made. Thus, the power of the SAPS II score to predict death as associated with the weaning categories may have been weakened by the loss of the most severely ill patients.

The mean length of stay in ICU was significantly prolonged in patient with post extubation distress. This coincided with a recent retrospective study of Chung et al. (2020) who established a model for predicting extubation based on the predictive factors of successful extubation. This result could be attributed to the more severity and more associated comorbidities of those patients with prolonged ICU stay.

As regard the mean duration of $\mathrm{MV}$, patients with post extubation distress and patients with post extubation success showed a statistically significant difference. This finding matches with those of Abdel Rahman et al. (2020) who showed that prolonged mechanical ventilation of critically ill patients is associated with higher rates of mortality and morbidity.

These results show that the means of SAPS II, length of ICU stay and duration of MV have great effect on weaning process and considered critical causes of post extubation distress.

Among patients who successfully pass SBT, the derecruitment was greater in patients who developed postextubation distress than in those who were definitively weaned. Ferré et al. (2019) concluded a similar observation in their study which included 42 patients and aimed at detecting weaning-induced pulmonary edema (WIPO) using lung ultrasound.

In patients who successfully passed the SBT, a lung ultrasound score $\leq 10$ at the end of the SBT was highly predictive of postextubation success with a statistically significant difference. On the other hand, lung ultrasound score $\geq 18$ at the end of the SBT was highly predictive of postextubation distress with a statistically significant difference. Similarly, Soummer et al. (2012) reported that LUS score less than 13 was associated with extubation success, while LUS score more than 17 was associated with extubation failure (EF) in ventilated adults.

On MV, before the SBT, we found significant differences in $\mathrm{E} / \mathrm{A}$ ratio in patients with spontaneous breathing trial success and in patients with spontaneous breathing trial failure with a statistical significant. There was in agreement with Ait-Oufella et al. (2012) in the study of patients undergoing a spontaneous breathing trial on a T-tube to assess the cardiac consequences of successful respiratory weaning using the variations of circulating B-type and atrial natriuretic peptides (BNP, ANP) and Doppler mitral flow.

\section{CONCLUSION}

The use of transthoracic ultrasound aimed at assessing lung aeration changes during SBT, a new, easy-to-perform, and noninvasive measurement, may contribute to reducing the occurrence rate of postextubation distress, a clinical condition associated with increased morbidity and mortality. Assessment of Lung aeration and LV diastolic function before attempting a weaning process 
could be useful in the detection of patients likely to fail weaning.

\section{REFERENCES}

1. Abdel Rahman, Dalia A, Saber S, and ElMaghraby A (2020): Diaphragm and lung ultrasound indices in prediction of outcome of weaning from mechanical ventilation in pediatric intensive care unit. The Indian Journal of Pediatrics, 87: 413-420.

2. Ait-Oufella H, Tharaux PL, Baudel JL, Vandermeersch S, Meyer $P$ and Tonnellier M (2012): Variation in natriuretic peptides and mitral flow indexes during successful ventilatory weaning: a preliminary study. Intensive Care Med., 33:1183-1186.

3. Boles JM, Bion J, Connors A, Herridge M, Marsh B, Melot C, Pearl R and Silverman H. (2011): Weaning from mechanical ventilation. Eur Respir J., 29:1033-56

4. Chung, Chan W, Sheu CC, Hung JY, Hsu TJ, Yang SH, and Tsai JR (2020): Novel mechanical ventilator weaning predictive model. The Kaohsiung journal of medical sciences, 36: 841-849.

5. Ferre, Alexis, Guillot M, Lichtenstein D, Meziere G, Richard C, Teboul JL, and Monnet. X (2019): Lung ultrasound allows the diagnosis of weaning-induced pulmonary oedema. Intensive care medicine, 45: 601608.

6. Girard TD, Alhazzani $W$ and Kress JP (2017): Liberation from Mechanical Ventilation in Critically Ill Adults. Rehabilitation Protocols, Ventilator Liberation Protocols, and Cuff Leak Tests. Am J Respir Critical Care Medicine, 195:120-129.
7. Heunks, L. M., and Van Der Hoeven, J. G. (2010): Clinical review: The $\mathrm{ABC}$ of weaning failure-a structured approach. Critical Care, 14(6): 1-9.

8. Nemer SN, Barbas CS and Caldeira JB (2011): A new integrative weaning index of discontinuation from mechanical ventilation. Critical Care, 13: 152-157.

9. Penuelas, Oscar, Frutos-Vivar F, Fernandez C, Anzueto A, Epstein SK, Apezteguia C, and Gonzalez M (2011): Characteristics and outcomes of ventilated patients according to time to liberation from mechanical ventilation. American journal of respiratory and critical care medicine, 184(4): 430-437.

10. Schmidt, Gregory A, Timothy D, Girard, Kress JP, Morris PE, Ouellette DR, Alhazzani W, and Burns SM (2017): Official executive summary of an American Thoracic Society/American College of Chest Physicians clinical practice guideline: liberation from mechanical ventilation in critically ill adults. American journal of respiratory and critical care medicine, 195: 115-119.

11. Silva $S$, Aissa $D$, Cocquet $P$, Hoarau $L$, Ruiz J, Ferre F, Rousset D, Mora M, Mari $A$, Fourcade $O$, Riu $B$, Jaber $S$, and Bataille B. (2017): Combined Thoracic Ultrasound Assessment during a Successful Weaning Trial Predicts Postextubation Distress. Anesthesiology, 127(4): 666-674.

12. Soummer, Alexis, Perbet $S$, Brisson $H$, Arbelot C, Constantin JM, Lu Q, and Rouby JJ (2012): Ultrasound assessment of lung aeration loss during a successful weaning trial predicts postextubation distress. Critical care medicine, 40(7): 2064-2072. 
الاستخدام التكاملى للموجات فوق الصوتية السريرية على تلى الرئة و تخطيط صدى القلب كمتنبئات مساعدة لعملية الفطام الناجحة

أحمد محمد عبدالله محمد بشير، إسماعيل عبدالمنعم عطية، محمود السعيد أحمد،

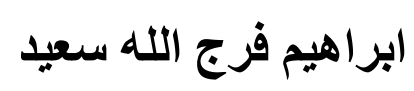

قسم الأمراض الصدرية و قسم القلب والأوعية الاموية، كلية الطب، جامعة الأزهر، القاهرة

E-mail: ahmedbeshir.6@azhar.edu.eg

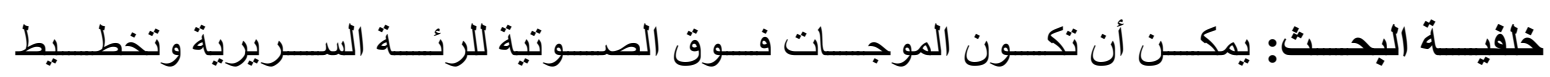

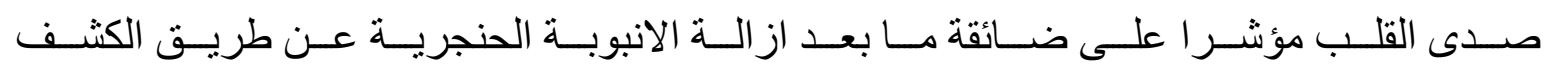

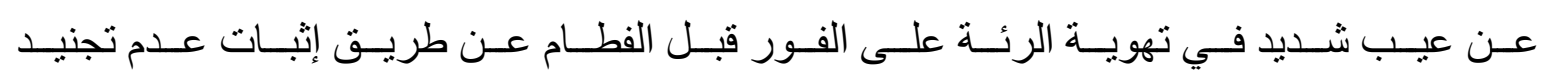
الرئة بشكل كبير أثناء تجربة التنفس التلقائي.

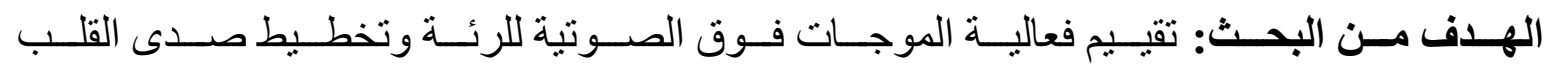

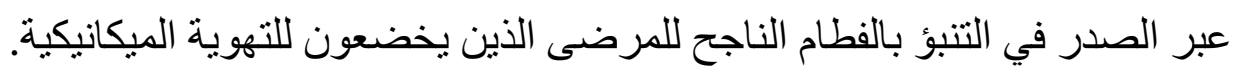

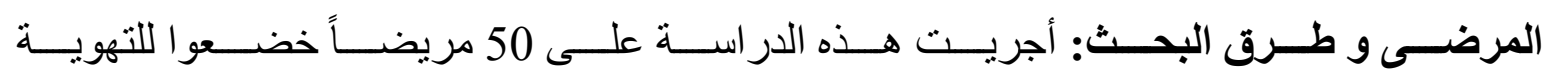

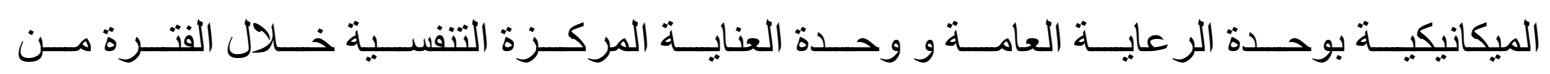

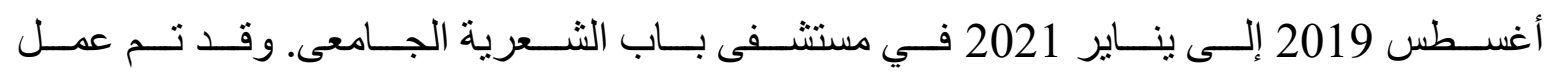

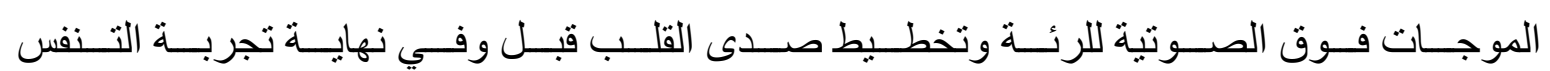

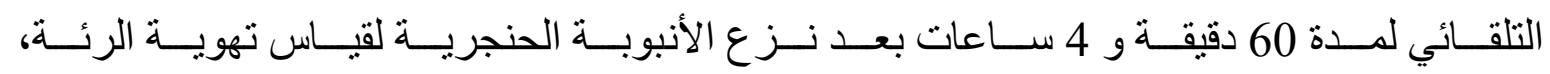
و تم حساب درجة الموجات فوق الصوتية للرئة.

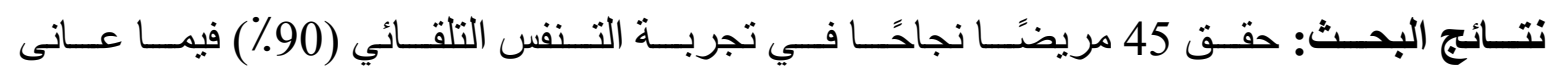

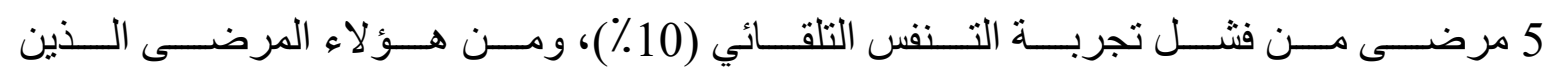

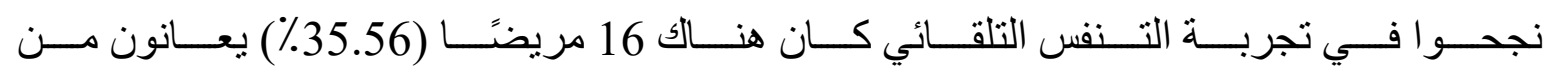

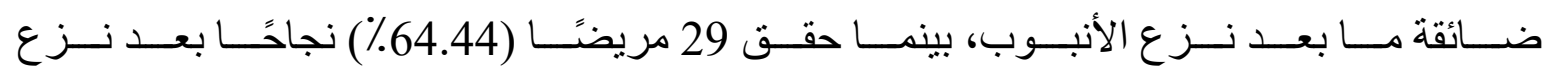

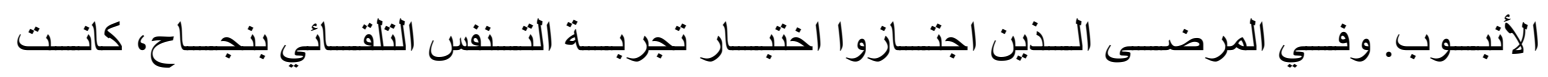

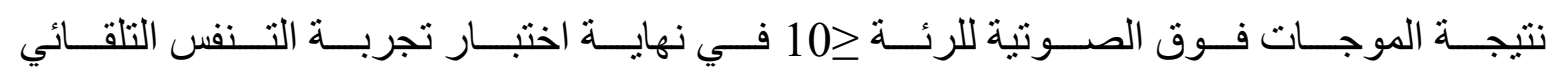




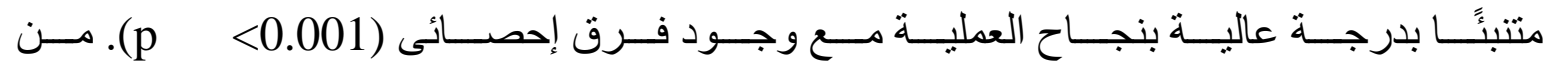

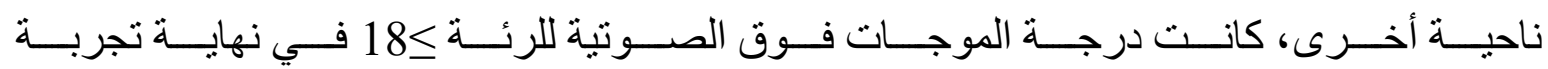

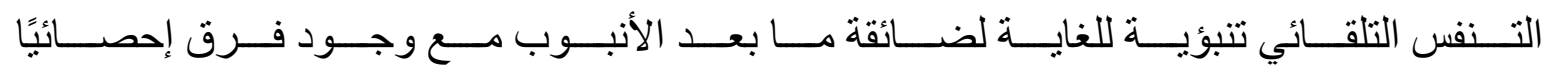

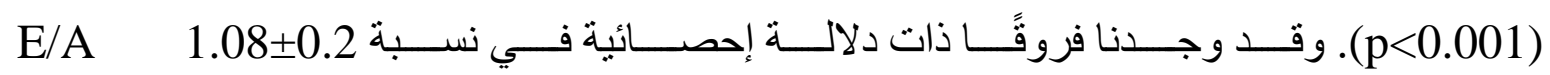

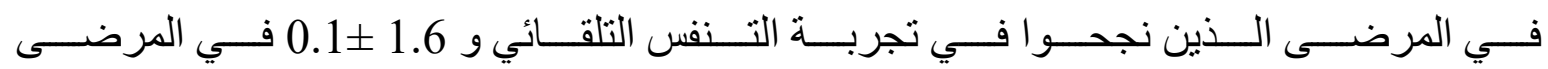

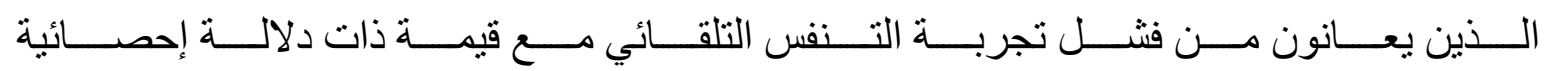
. $(\mathrm{P}<0.001)$

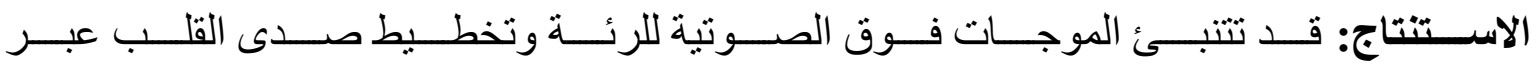
الصدر أثناء تجربة التنفس التلقائي لحدوث ضائقة ما بعد از الة الأنبوبة الحنجرية.

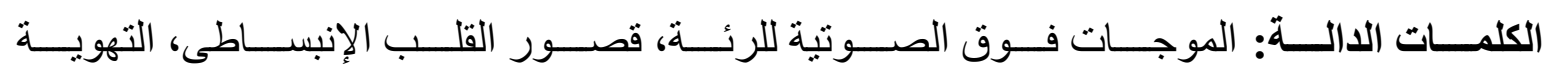
الميكانيكية، الفطام. 